\title{
Dopaminergic Microtransplants into the Substantia Nigra of Neonatal Rats with Bilateral 6-OHDA Lesions. I. Evidence for Anatomical Reconstruction of the Nigrostriatal Pathway
}

\author{
Guido Nikkhah, ${ }^{1,2}$ Miles G. Cunningham, ${ }^{3}$ Maria A. Cenci, ${ }^{1}$ Ronald D. McKay, ${ }^{4}$ and Anders Björklund' \\ ${ }^{1}$ Department of Medical Cell Research, University of Lund, S-223 62 Lund, Sweden, ${ }^{2}$ Neurosurgical Clinic, \\ Nordstadt Hospital, D-30167 Hannover, Germany, ${ }^{3}$ Harvard Medical School, Boston, Massachusetts 02115, and 4 \\ Laboratory of Molecular Biology, NINDS NIH, Bethesda, Maryland 20892
}

Reconstruction of the nigrostriatal pathway by long axon growth derived from dopamine-rich ventral mesencephalic (VM) transplants grafted into the substantia nigra may enhance their functional integration as compared to VM grafts implanted ectopically into the striatum. Here we report on a novel approach by which fetal VM grafts are implanted unilaterally into the substantia nigra (SN) of 6-hydroxydopamine (6-OHDA)-lesioned neonatal pups at postnatal day 3 (P3) using a microtransplantation technique. The results demonstrate that homotopically placed dopaminergic neurons survive and integrate well into the previously 6-OHDA-lesioned neonatal SN region. Moreover, the tyrosine hydroxylase (TH)-positive neurons extended axons rostrally along the white matter tract of the internal capsule closely following the course of the original nigrostriatal pathway. The graft reestablished a TH-positive axon terminal network in the ipsilateral caudate-putamen, with the highest density in the medial and central parts. Retrograde labeling with Fluoro-Gold from the host striatum demonstrated that most of the transplant neurons giving rise to the graft-derived fiber outgrowth were TH-positive, but revealed also a small proportion of projecting neurons which were TH-negative. Amphetamine-induced striatal Fos expression was normalized in the caudate-putamen ipsilateral to the intranigral VM grafts, showing hyperexpression in some areas of the striatum, and the apomorphine-induced Fos expression seen in the 6-OHDA-lesioned animals was completely reversed on the grafted side. These findings indicate that the graft-derived dopaminergic reinnervation of the striatum is functional.

The microtransplantation strategy may provide new avenues for the exploration of morphological and functional integration of fetal dopamine neurons in the nigrostriatal system and give new insights into the mechanisms controlling long-distance axon growth in the brain.

Received July 22, 1994 revised Nov. 17, 1994; accepled Nov. 29, 1994

We gratefully acknowledge the excellent technical support of Gertrude Stridsberg. Ulla Jarl, Maria Entezarjou, Agneta Persson, and Sten Nilsson. We warmly thank Prof. Majid Samii and Prof. Roberı Schommayr for their continuous support and Dr. Ivar Mendez for valuable suggestions on the manuscript. This study was supported by grants from Swedish MRC (04X-3874), the National Institute of Health (NS-0670)1), and the Goran Gustafsson Foundation G.N. was supported by a grant from the Deutsche Forschungsgemeinschaf (DFG Ni 330/1-1).

Correspondence should be addressed to Guido Nikkhah, Neurosurgical Clinic, Nordstadt Hospital, Haltenhoffstrasse 41, D-30167 Hannover 1, Germany.

Copyright (c) 1995 Society for Neuroscience $0270-6474 / 95 / 153548-14 \$ 05.00 / 0$
[Key words: target reinnervation, axon growth, neural transplantation, tyrosine hydroxylase immunohistochemistry, Fos protein, Fluoro-Gold]

In the lesioned brain of adult recipients dopamine-rich grafts from fetal ventral mesencephalon (VM) are unable to reinnervate the caudate-putamen unless they are placed close to, or within, the denervated target structure (Björklund et al., 1983b; Nikkhah et al., 1994b). The failure of regenerating dopaminergic axons to reinnervate the striatum from more distant implantation sites, including their normal site of origin, the substantia nigra $(\mathrm{SN})$, may at least in part be due to inhibitory factors present along the trajectory of the pathway, as suggested for other myelinated fiber tracts in the CNS (Schnell and Schwab, 1990; Schwab, 1990, 1993), and for the absence of adequate substraterelated guidance cues in adult host.

Attempts to reconstruct the nigrostriatal pathway in adult 6-OHDA-lesioned rats by fetal VM grafts have employed bridges formed by strings of fetal striatal tissue spread along a single tract through the frontal pole and the caudate-putamen to the SN (Dunnett et al., 1989). In some cases VM transplants implanted into the $\mathrm{SN}$ region were observed to extend $\mathrm{TH}$-positive fibers along the striatal bridge graft and extend terminals in the previously denervated host striatum. In support of these morphological findings, Dunnett et al. (1989) observed a significant reduction in amphetamine-induced rotational asymmetry in the bridge-grafted animals.

In an alternative approach, xenografts of fetal human neuroblasts implanted into adult rats, have been found to be able to emit long axonal growth along white matter tracts. Thus, intrastriatal grafts of human fetal striatal primordia have been shown to project axons along the striatonigral tract (Wictorin et al., 1990), and human fetal VM neuroblasts can exhibit extensive axonal elongation along the nigrostriatal pathway (Wictorin et al., 1992). Similar results have been obtained also with grafts of embryonic mouse hippocampal neurons which can grow into the spinal cord (Li and Raisman, 1993), the fimbria (Davies et al., 1993), or the corpus callosum (Davies et al., 1994). These data suggest that fetal CNS neurons may under certain circumstances be able to escape the inhibition exerted by the adult brain environment. In developing animals the ability of fetal CNS grafts to establish long axonal pathways has been well documented. In particular, highly organized and specific axonal projections have been demonstrated from grafts of fetal cortex implanted into the cerebral cortex (Floeter and Jones, 1984; Castro et al., 1985; 
Stanfield and O'Leary, 1985; Hefner et al., 1990), from grafts of hippocampal neurons in the hippocampus (Sunde et al., 1984; Zimmer et al., 1987) and for retinal ganglion cells in the retinotectal system (Hankin and Lund, 1987, 1990; Lund et al., 1988) in neonatal recipients. A similar developmental plasticity has been demonstrated for fetal spinal cord grafts implanted into the neonatally lesioned spinal cord associated with signs of functional restoration (Iwashita et al., 1994).

Attempts to achieve reconstruction of the nigrostriatal system in neonatal hosts have so far not been reported, probably due to the difficulties in performing transplantation into small structures in the neonatal brain. Ectopically implanted intrastriatal VM grafts have been explored in 6-OHDA-lesioned neonatal rat pups (Snyder-Keller et al., 1989; Herman et al., 1991; Abrous et al., 1993a-c). Even though the grafted TH-positive neurons showed more extensive morphological integration and migration within the caudate-putamen than in adult recipients, the behavioral compensation induced by these grafts was no different from that seen with grafts implanted into the striatum in adult hosts. Interestingly, graft-derived TH-positive neurites were seen to course through the corpus callosum to reach the contralateral hemisphere (Herman et al., 1991), which indicates, that the neonatal brain may permit TH-positive fiber growth through white matter tracts, and, hence, that the nconatal brain may provide a more favorable environment for dopamine growth and integration.

Recently, we have introduced a microtransplantation approach which allows precise and reproducible placements of small graft deposits, suitable for intracerebral grafting during development (Nikkhah et al., 1994c). The purpose of the present study was to investigate whether intranigral VM grafts, implanted homotopically into the 6-OHDA-lesioned SN of neonatal pups, could demonstrate long-distance axon growth towards their normal major target, the caudate-putamen, and to analyze the functional effects such grafts may have when testing the animals in adulthood. The grafted animals were tested on a range of spontaneous and drug-induced behaviors, which is described in detail in the following companion report (Nikkhah et al., 1995). Here we report that grafts implanted into the SN of P3 hosts can successfully reinnervate the caudate-putamen and form functional connections as assessed by dopamine-related Fos expression in the reinnervated target.

\section{Materials and Methods}

Animals and 6-OHDA lesion surgery. A total of 52 male and female Sprague-Dawley rats (ALAB, Stockholm, Sweden) were used in the experiments. Litters were reared by the mothers until weaning at $21 \mathrm{~d}$ of age. They were housed under a $12 \mathrm{hr}$ light-dark cycle with free access to food and water in groups of four to six following weaning. Animals were allocated into three groups: normal $(n=10), 6-O H D A$ $(n=20)$, and graft $(n=22)$ groups. On the day after birth (Postnatal day $P 1$ ) the animals in the 6-OHDA and graft groups received bilateral intraventricular injections of $2 \times 5 \mu \mathrm{l}$ 6-OHDA (110 $\mu \mathrm{g}$ of 6-OHDA $\mathrm{HCL}$ in $0.2 \mathrm{mg} / \mathrm{ml}$ ascorbic acid/saline) using the coordinates: AP -0.6 , $\mathrm{L} \pm 0.8, \mathrm{~V} 2.1$. Grafting was performed $2 \mathrm{~d}$ later (P3). Following lesion and transplantation surgery a battery of tests for spontaneous and druginduced behavior was performed, as described in detail in the following companion article (Nikkhah et al., 1995). During this period seven lesioned and nine grafted animals died, most likely due to cardiovascular decompensation, after the amphetamine rotation test at P21.

Neonatal transplantation surgery. Transplants of dopamine-rich cell suspensions were prepared from ventral mesencephalic (VM) tissue of $14 \mathrm{~d}$ old rat fetuses (E14) according to a modified microtransplantation approach (Nikkhah et al., 1994c) based on the cell suspension technique (Björklund et al., 1983a; Herman et al., 1986). VM tissue from 20-25 fetuses were used in each surgical session. The VM pieces were incu- bated in $0.1 \%$ trypsin $/ 0.05 \%$ DNase $/ D M E M$ at $37^{\circ} \mathrm{C}$ for $20 \mathrm{~min}$, rinsed four times in $0.05 \%$ DNase, and mechanically dissociated using a $1 \mathrm{ml}$ Eppendorf pipette. The tissue was then centrifuged at $600 \mathrm{rpm}$ for 5 min and the pellet resuspended in $0.05 \%$ DNase/DMEM. The ecll number of this suspension was 140,000 cells $/ \mu \mathrm{l}$ and the viability was $>95 \%$ as determined by the trypan blue dye exclusion method.

The transplantation surgery on P3 animals was performed in two surgical sessions as described in detail elsewhere (Cunningham et al., 1993). Briefly, P3 animals were fixed in the Cunningham hypothermic miniaturized stereotaxic device (Cunningham and McKay, 1993; Stoelting Co.). The micrografts were implanted using a glass capillary with an O.D. of $50-70 \mu \mathrm{m}$ connected to a $1 \mu 1$ Hamilton microsyringe; 300 $\mathrm{nl}$ of the cell suspension was implanted unilaterally into the right $\mathrm{SN}$ at two sites: AP (1) -3.7 (2) $-4.3, \mathrm{~L}+1.6, \mathrm{~V}-4.3$

Drug treatment and immunohistochemical procedures. At 3 months of age $d$-amphetamine $(5 \mathrm{mg} / \mathrm{kg}$, i.p.; five grafted, five lesioned, and four normal animals) or apomorphine $(0.25 \mathrm{mg} / \mathrm{kg}$, s.c.; five grafted, five lesioned, and four normal animals) were injected. Two hours after injection the animals were deeply anaesthetized with choral hydrate and perfused transcardially with $30 \mathrm{ml}$ of $0.9 \%$ saline, followed by $300 \mathrm{ml}$ of ice-cold $4 \%$ parafonmaldehyde in $0.1 \mathrm{~m}$ phosphate buffer $(\mathrm{PB}, \mathrm{pH}$ 7.4) over $9 \mathrm{~min}$. The brains were postfixed for 2 hours and dehydrated overnight in $20 \%$ sucrose, 0.1 M PB. Serial coronal sections were cut on a freezing microtome at $30 \mu \mathrm{m}$ thickness. Every third section through the striatum was processed for Fos immunohistochemistry as described previously (Cenci et al., 1992). Briefly, sections were incubated overnight with the primary antibody $(1: 1000$, sheep polyclonal antiserum OA-11-823, Cambridge Research Biochemical, U.K.) using the $\mathrm{ABC}-\mathrm{K}$ it and nickel-intensified DAB for visualization

From each animal one series of sections extending from the nucleus accumbens, rostrally, to the end of the SN, caudally, was processed for tyrosine hydroxylase (TH) immunohistochemistry (1:500, rabbit polyclonal antiserum, Pel-Freez, USA; Nikkhah et al., 1994a) using the $\mathrm{ABC}-\mathrm{Kit}$ and $\mathrm{DAB}$ for visualization. Remaining animals, not challenged wilh drugs, were processed as above at 3 months of age. Serial sections in the coronary plane were processed either for $\mathrm{TH}$, as above, or for combined TH-FG using FITC immunofluorescence (see below).

Quantitative analysis of drug-induced Fos expression. Striatal Fos expression after amphetamine and apomorphine treatment was assessed according to the procedure described by Cenci et al. (1992). Briefly, Fos-positive nuclei were counted in each animal in 10 different areas $\left(0.42 \mathrm{~mm}^{2}\right.$ in size $)$ at four different rostrocaudal levels of the caudateputamen as well as in the nucleus accumbens and the globus pallidus (see Fig. 6A) using a computerized image analysis system (Zeiss IBAS, Kontron). For statistical evaluation, data were subjected to one-way analysis of variance (ANOVA) and Newman Keuls post hoc test. Statistical significance level was set at $p<0.05$.

Fluoro-Gold injections into the caudate-putamen. The fluorescent retrograde tracer Fluoro-Gold (FG; Fluorochrone Inc.; 2\% in saline) was injected by iontophoresis into the right caudate-putamen in five grafted, five lesioned, and two normal animals at the following two injections sites: (1) AP +0.5, L +2.5, V - 4.5; (2) AP $-0.5, \mathrm{~L}+3.5, \mathrm{~V}-4.5$. The technical details of this procedure have been described in detail previously (Wictorin et al., 1989). Two of the grafted and lesion-only animals were injected with apomorphine and included in the Fos experiment above. One series of sections was directly mounted onto slides, coverslipped with buffered glycerol and analyzed in a fluorescence microscope at $365 \mathrm{~nm}$ excitation. Adjacent sections were immunostained for simultaneous $\mathrm{TH}$ and $\mathrm{FG}$ visualization in the same section. $\mathrm{TH}$ immunohistochemistry was performed using the primary antibody at 1:50 to $1: 100$ dilution overnight (Peel-Freez), and a secondary fluorescein isothiocyanate (FITC) conjugated antibody (SBL, Stockholm, Sweden) at a 1:30 dilution for $1 \mathrm{hr}$ at room temperature. Double labeled cells in the substantia nigra region were examined and photographed by switching between $365 \mathrm{~nm}$ and $450-490 \mathrm{~nm}$ excitation.

\section{Results}

TH immunohistochemistry

Consistent with previous studies (Snyder et al., 1986; Abrous et al., 1993b) we found that the neonatal intraventricular 6-OHDA lesion produced an almost complete lesion of the TH-positive neurons in the SN proper, but tended to spare those in the ventral tegmental area (VTA) (Figs. 1, 3). Accordingly, only few scattered TH-positive fibers remained in the caudate-putamen 

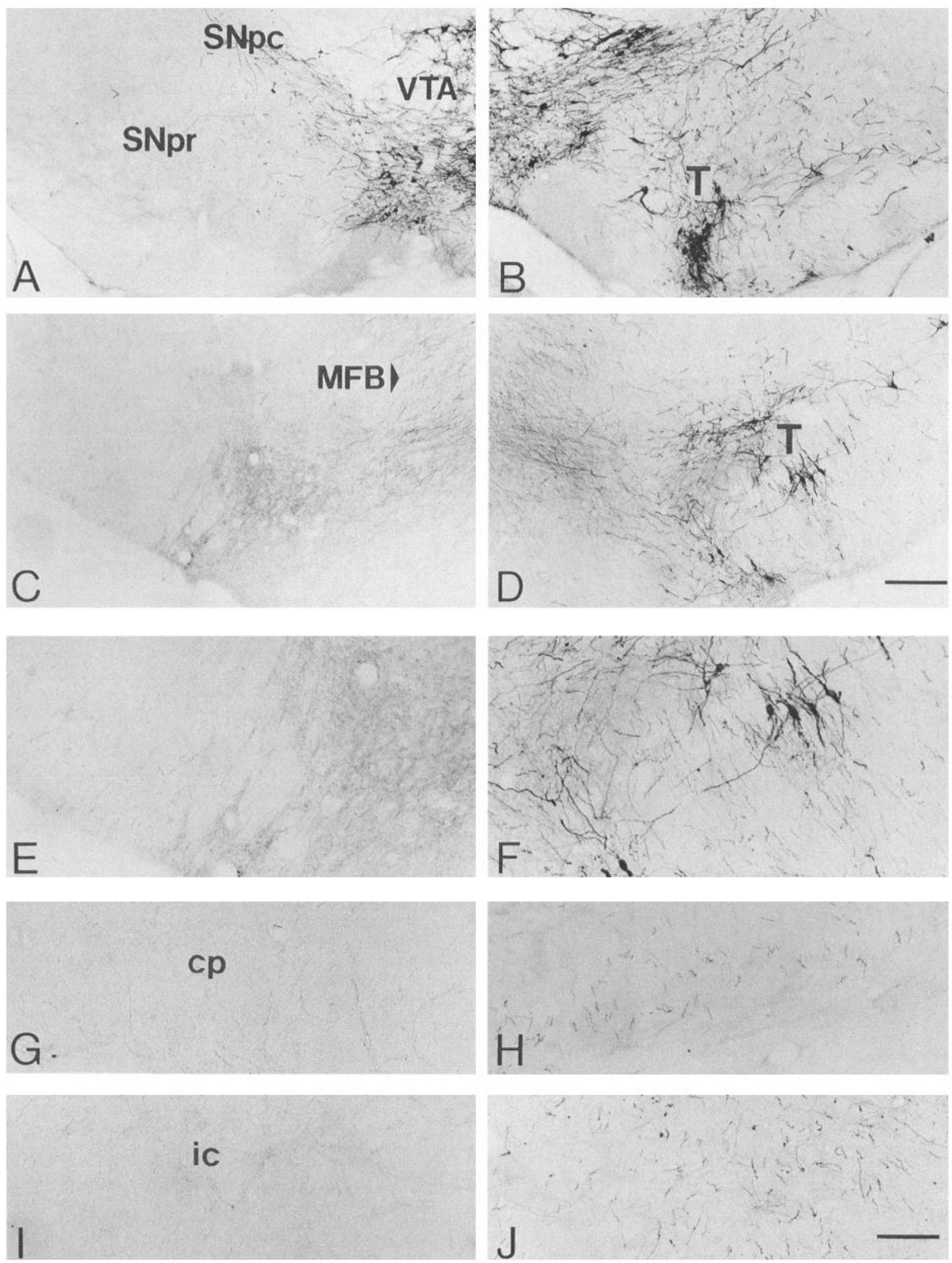

Figure 1. TH-immunostained sections at four representative levels through the SN, internal capsule and globus pallidus in an animal which received bilateral 6-OHDA lesions at P1 and a unilateral nigral graft at P3. Grafted TH-positive neurons could be seen in the ventral part of the $\mathrm{SNpr}$, extruding into the cerebral peduncle $(B ; \mathrm{AP}-6.7)$. The rostral graft deposit was well integrated in the anterior part of the SN $(D ; \mathrm{AP}-5.2)$. Numerous TH-positive fibers extended from the grafted cells into the white matter forming a lose bundle, which could be traced further rostrally along the cerebral peduncle $(F$; AP -2.8$)$ through the globus pallidus $(H$; AP -2.3$)$ into the caudate-putamen. The contralateral lesion-only side was almost totally devoid of TH-positive neurons in the $\mathrm{SN}(A, C)$ and no or very few TH-positive fibers were seen along the nigrostriatal pathway $(E, G)$. $c p$, Cerebral peduncle; $i c$, internal capsule; $M F B$, medial forebrain bundle; $S N p c$, substantia nigra pars compacta; $S N p r$, substantia nigra pars reticulata; $T$, transplant; VTA, ventral tegmental area. The AP coordinates used here and in Figure 3 refer to the atlas of Paxinos and Watson (1986). Scale bar, $100 \mu \mathrm{m}$. 

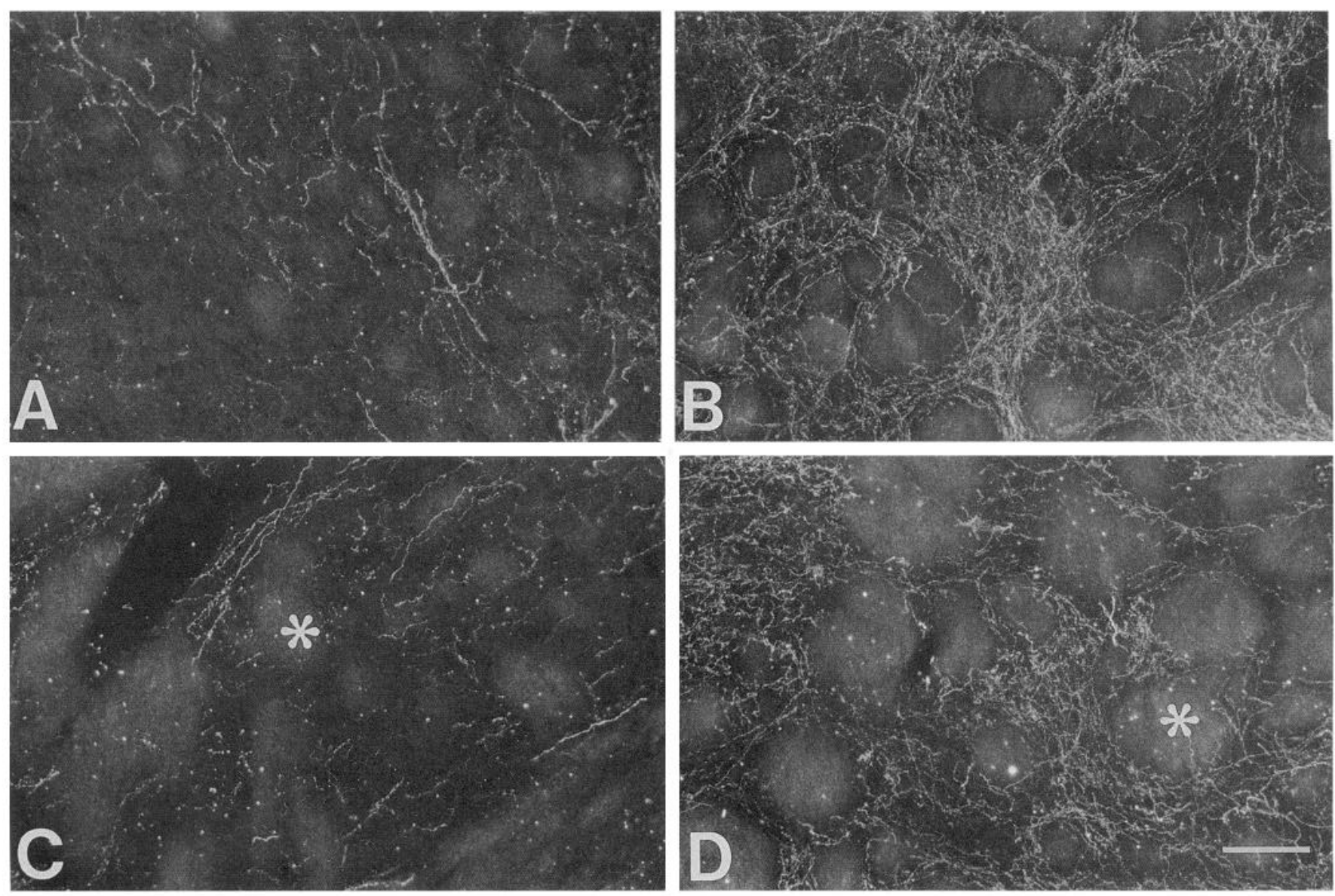

Figure 2. Dark-field photomicrographs, from the same specimen as in Figure 1, illustrating abundant TH-positive fibers in the medial $(B)$ and central $(D)$ portion of the caudate-putamen ipsilateral to the intranigral VM graft and only few scattered TH-positive fibers in the medial $(A)$ and central part $(C)$ of the contralateral lesion-only caudate-putamen. There was a decreasing density of TH-positive fibers from medial to lateral. *, Fiber bundles of the internal capsule. Scale bar, $100 \mu \mathrm{m}$.

whereas the dopaminergic innervation in the mesolimbic areas was relatively spared. Thus, the graft-derived TH-positive fibers could not clearly be differentiated from residual host $\mathrm{TH}$-positive fibers, for example, in the nucleus (nc) accumbens, the olfactory tubercle or the amygdala.

Transplants of E14 fetal VM tissue were implanted at P3 as two single $0.3 \mu \mathrm{l}$ deposits into the right $\mathrm{SN}$ region in pups that had received intraventricular 6-OHDA injections at P1. Two representative examples of the appearance of intranigral VM grafts and their rostral projections 3 months postgrafting are given in Figures 1-3. The grafts survived well and demonstrated a high level of integration, which was seen in all of the 13 surviving animals. Grafts from the posterior deposits were found in the ventral part of the SN pars reticulata (SNpr), extruding in some cases into the cerebral peduncle (Fig. $3 B, D$ ). The anterior deposits were located at the rostral tip of the $\mathrm{SN}$ close to the subthalamic nucleus. TH-positive neurons were dispersed in both gray and white matter and appeared to be completely integrated with the host tissue (Figs. 1D, 3B). Occasionally, clumps of TH-rich graft tissue occurred at the ventral brain surface, attached to the cerebral peduncle (Fig. $3 D$ ), and in some cases TH-positive cells were found scattered along the needle tract (Fig. 4C) and at the dorsal thalamic surface indicating that some back-leakage had occurred.

Numerous TH-positive fibers extended from the grafted neu- rons into the adjacent white matter of the cerebral peduncle forming loose bundles of projecting axons (Figs. 1A,D;3F). These TH-positive fibers could be traced rostrally (but not caudally) along the cerebral peduncle and the internal capsule along a trajectory that closely followed that of the normal nigrostriatal pathway. At the level of the caudal hypothalamus the TH-positive fibers coursed through the ventral aspect of the cerebral peduncle spread along its medial-lateral extension (Fig. 1F). Further rostrally the fibers penetrated the globus pallidus (Figs. $1 \mathrm{H}, 3 \mathrm{H})$ and extended further to reinnervate the caudate-putamen (Fig. 2B,D). Reinnervation of TH-positive fibers within the ipsilateral caudate-putamen was heterogeneous. The density of fibers was highest within the dorsomedial part (Fig. 2B), gradually decreasing towards the central and lateral parts of the caudate-putamen (Fig. 2D). No or only single, scattered TH-positive neurons occurred within the $\mathrm{SN}$ on the contralateral non-grafted side in the grafted animals, or bilaterally in the lesion-only controls. Very few TH-positive fibers remained along the nigrostriatal pathway on the lesioned side (Figs. 1, 3A,C,E,G), and on this side (contralateral to the grafts) the caudate-putamen had as few TH-positive fibers as in the lesion-only controls (Fig. $2 A, C$ ). On the nongrafted side, as well as in the lesion-only specimens, consistently no mediolateral gradient in the caudateputamen could be seen (Fig. 2A,C).

Spared $\mathrm{TH}$-positive neurons occurred in varying numbers in 


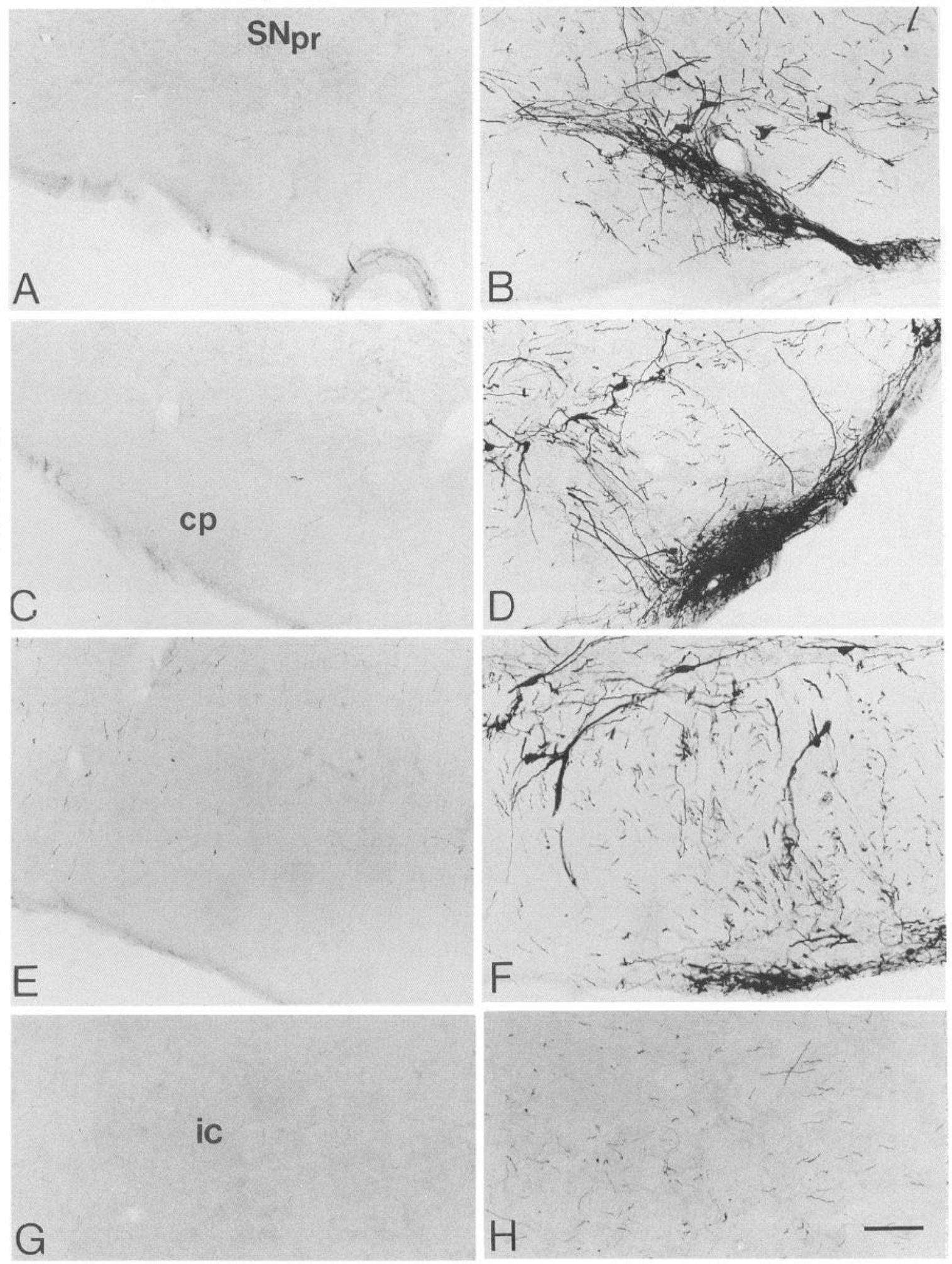

Figure 3. TH-immunostained sections of another lesioned and grafted animal showing four representative levels throughout the ventral part of the SN, the cerebral peduncle and the internal capsule. Dense clusters of transplant-derived TH-positive neurons $(B ; \mathrm{AP}-4.8 ; D ; \mathrm{AP}-4.5)$ gave rise to an abundant $\mathrm{TH}$-positive fiber outgrowth coursing through the cerebral peduncle $(F ; \mathrm{AP}-4.2)$ and the internal capsule $(H ; \mathrm{AP}-2.3)$. In contrast, the lesion-only contralateral side were almost completely depleted of any nigral TH-positive neurons and TH-positive fibers. $c p$, Cerebral peduncle; $i c$, internal capsule; $S N p r$, substantia nigra pars reticulata. Scale bar, $100 \mu \mathrm{m}$. 

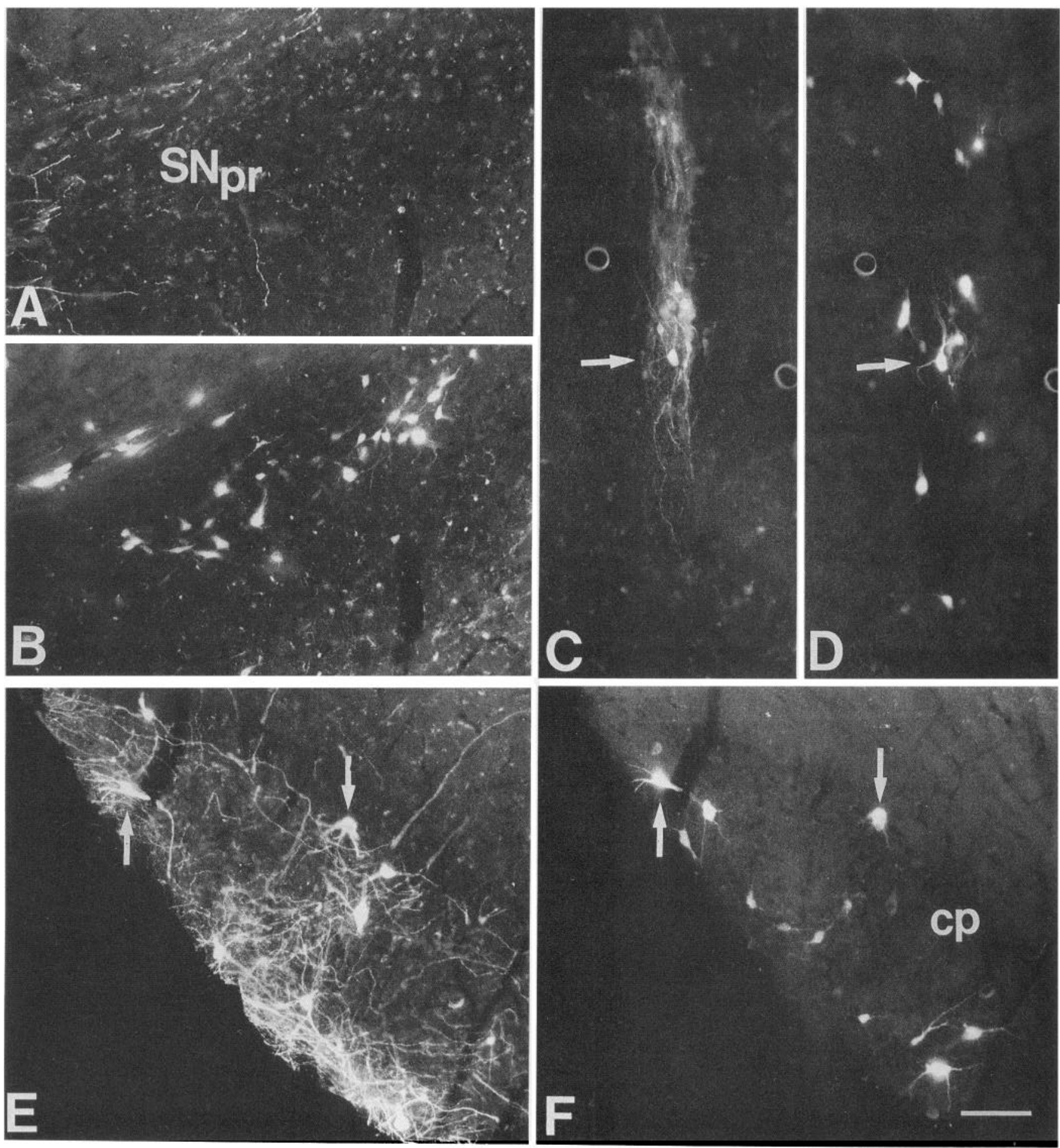

Figure 4. Examples of host and graft neurons retrogradely labeled from an intrastriatal FG injection. Concomitant visualization of TH $(A, C$, $E$ ) and FG $(B, D, F)$ in the same sections through the rostral SN. Fluorescence photomicrographs illustrate numerous TH-negative $(A)$ and FG-positive $(B)$ cells in the lesion-only SN, especially in the SNpr. In the $\mathrm{SN}$, which had received a VM graft, clusters of TH-positive neurons were found along the needle tract $(C)$ and, in this case also in the cerebral peduncle $(E)$; some of these cells were also double labeled $(a r r o w s)$ with FG $(D$, $F)$. Scale bar, $100 \mu \mathrm{m}$.

the VTA, that is, medial to the SN, and spared TH-positive axons were found within the medial forebrain bundle on both sides.

\section{Double labeling with $T H$ and FG}

In order to provide further evidence for the projection of graftderived $\mathrm{TH}$-positive fibers from the intranigral VM implants to the caudate-putamen, the retrograde tracer Fluoro-Gold (FG) was injected unilaterally into the caudate-putamen in five grafted, five lesion-only controls, and in two normal intact rats. The two intrastriatal FG injections sites were well centered within the head of the caudate-putamen with a small, necrotic core surrounded by a $1-1.5 \mathrm{~mm}$ wide halo of cellular labeling (not 
shown). In the normal animals the FG injections resulted in a prominent retrograde labeling of the ipsilateral SN pars compacta (SNpc) neurons, but also of cells situated in the cortex and in the thalamus (not shown). In the lesion-only animals no or single TH- and FG-double labeled cells could be identified in the SN (Fig. $4 A, B$ ). Interestingly, there seemed to be an increase in the number of TH-negative cells that were retrogradely labeled with $F G$ in the SNpr in the lesioned rats. Labeled cells within the intranigral VM transplants could be identified in all of the five grafted and FG-injected rats. These cells displayed three different kinds of labeling patterns: (1) TH- and FG-double labeled (positive), (2) TH-positive FG-negative, and (3) TH-negative FG-labeled (Figs. 4, 5). Some of the double-labeled cells were clearly located in the SN (Fig. 5) while others occurred in ectopic positions (Fig. $4 C-F$ ). A cluster of TH-positive cells distributed along the needle tract just above the $\mathrm{SN}$, is shown in Figure $4 C$. As can be seen from Figure $4 D$, some of these cells were also FG-labeled. A portion of a transplant located within the cerebral peduncle is shown in Figure $4, E$ and $F$. Doublelabeled cells and TH-positive neurites extending dorsally into the white matter tract could be observed.

Examples of implants located within or close to the SNpr are illustrated in Figure 5. It can be seen that the majority of the TH-positive cells (Fig. 5A,C,E,G) are retrogradely FG-labeled (Fig. $5 B, D, F, H$ ). There are, however, also clear cases of single labeled cells, both for TH and FG (Fig. 5A, $G, H$ ).

\section{Fos expression}

No consistent left-right side differences in Fos expression were seen in either the normal or the lesion-only animals. Therefore, in the quantitative analysis (Fig. 6) the values given for the normal and lesion-only animals represent the means of the two sides.

Amphetamine-induced Fos expression. Consistent with previous data (Cenci et al., 1992) the density of amphetamine-induced Fos-positive nuclei in the normal intact animals was highest in the centromedial portions of the caudate-putamen and lower in the lateral, ventral and rostral portions, including the nucleus accumbens (Fig. 6B). The number of Fos-positive nuclei ranged from $23 / 0.42 \mathrm{~mm}^{2}$ (in area I:2, Fig. $6 A$ ) to $117 / 0.42 \mathrm{~mm}^{2}$ (in area IV:2, Fig. 7A) in the caudate-putamen, and reached 46 and 31 Fos-positive nuclei/ $0.42 \mathrm{~mm}^{2}$ in the nucleus accumbens and the globus pallidus, respectively. The neonatal 6-OHDA lesion produced a marked bilateral decrease in the number of amphetamine-induced Fos-positive nuclei, which amounted to between $-50 \%$ and $-85 \%$ at levels III and IV in the caudate-putamen (Fig. $7 \mathrm{C}$ ), $-78 \%$ in the nucleus accumbens, and $-87 \%$ in the globus pallidus (Fig. $7 D$ ). Fewer Fos-positive cells were also seen at level I and II, but this change did not reach statistical significance.

In the grafted animals ( 3 months postgrafting) the numbers of Fos-positive nuclei on the grafted side were significantly increased above those seen either on the contralateral nongrafted side (crosses in Fig. 6) or in the lesion-only controls (asterisks), and they exceeded the values of the normal animals in most areas (Fig. $7 E$ ), from about $50 \%$ in area III: 2 to fivefold in area $\mathrm{I}: 2$. Fos expression was not different from normal in the nucleus accumbens, in areas III: 3 and IV:2 of the caudate-putamen, and in the globus pallidus (Fig. $7 F$ ). Only in one area (IV:3) did the number of Fos-positive nuclei remain below normal $(-42 \%)$. As in the normal striatum the grafted ipsilateral caudate-putamen displayed a decreasing gradient in the density of Fos-positive nuclei from medial to lateral at levels I, II, and III, and from dorsal to ventral at level III.

On the nongrafted lesioned side in the grafted animals the number of Fos-positive nuclei was generally not significantly different from the lesion-only rats after the amphetamine challenge, with two exceptions: areas III: 1 and III: 2 of the nongrafted caudate-putamen had significantly more (around threefold) Fos-positive nuclei than the corresponding areas in the lesion-only controls. In these areas Fos-expression was not significantly different from normal.

Apomorphine-induced Fos expression. In the intact animals Fos-positive nuclei were much lower in density and more evenly distributed after apomorphine challenge $(0.25 \mathrm{mg} / \mathrm{kg}$, s.c. $)$ than after the amphetamine treatment, and no mediolateral gradient was observed at levels I and II (Fig. 6C). The 6-OHDA lesion resulted in a striking increase in the density of apomorphineinduced Fos-positive nuclei throughout the caudate-putamen (see also Fig. 8A,C), nucleus accumbens and globus pallidus (see also Fig. $8 B, D$ ) with a marked dorsal-to-ventral gradient at levels III and IV of the caudate-putamen.

The increase in Fos expression reached its maximum in area I:1 where 161 Fos-positive nuclei/0.42 $\mathrm{mm}^{2}$ were seen in the lesion-only animals, compared to 2 nuclei/ $0.42 \mathrm{~mm}^{2}$ in the normals. In the grafted animals the numbers of Fos-positive nuclei on the grafted side were not significantly different from normal levels in all areas counted (see also Fig. $8 E, F$ ) and in most areas, including globus pallidus, they were significantly reduced compared to the lesion-only controls. On the nongrafted side, the density of Fos-positive nuclei in the caudate-putamen tended overall to be reduced to a level intermediate between those seen in the normal and lesion-only animals. This reduction reached significance in areas I:2, III:2, and IV:2, whereas Fos-expression in the contralateral nucleus accumbens and globus pallidus remained unchanged compared to the lesion-only animals.

\section{Discussion}

The present series of experiments demonstrate, for the first time, (1) that fetal nigral microtransplants survive and differentiate well when implanted homotopically into the 6-OHDA-lesioned $\mathrm{SN}$ in neonatal hosts, (2) that the grafted TH-positive neurons can grow axons from the $\mathrm{SN}$ along the course of the original nigrostriatal pathway, and (3) that the graft-derived dopaminergic reinnervation can normalize dopamine receptor-mediated Fos expression in the striatum and globus pallidus, and after amphetamine challenge even induce supranormal Fos responses in the reinnervated striatum.

Two small VM cell suspension grafts, each containing about 40,000 cells in a volume of $300 \mathrm{nl}$, were implanted unilaterally into the SN region in bilaterally 6-OHDA-lesioned neonatal rat pups. Three months after transplantation TH immunohistochemistry revealed a high level of anatomical integration of the grafted neurons into the host parenchyma. Moreover, graft-derived I'H-positive fibers could be seen to project rostrally along the cerebral peduncle and the internal capsule, coursing through the globus pallidus to produce a substantial terminal reinnervation within the caudate-putamen on the grafted side. The graft origin of the newly formed TH-positive terminal network in the caudate-putamen was confirmed by the retrograde labeling of $\mathrm{TH}$ positive graft neurons from an intrastriatal FG injection. The FG experiment also indicated the presence of a nondopaminergic projection from TH-negative neurons in the VM grafts. 

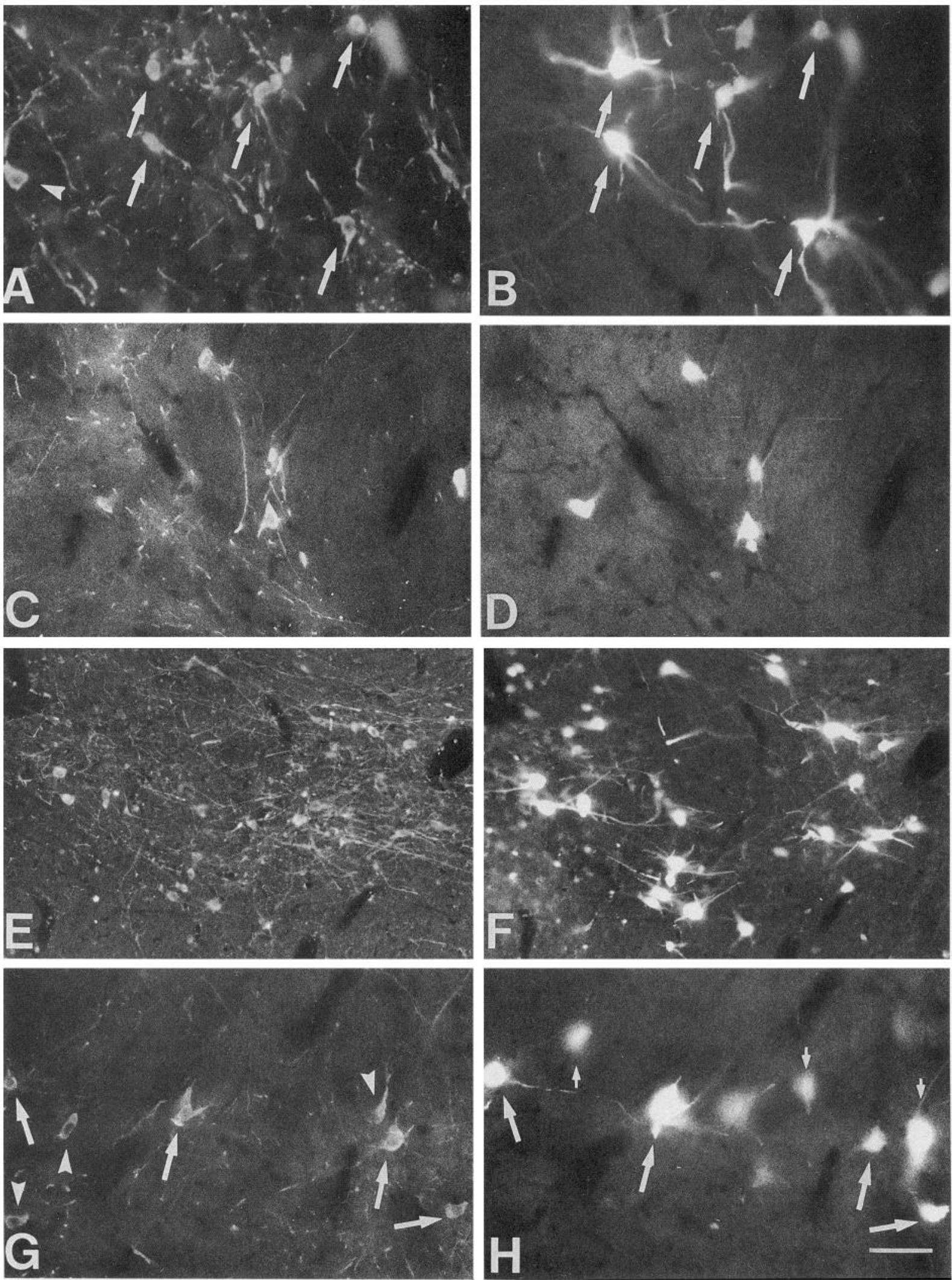

Figure 5. Concomitant visualization of $\mathrm{TH}(A, C, E, G)$ and $\mathrm{FG}(B, D, F, H)$ in the same sections through the $\mathrm{SN}$ of animals, which had received a bilateral 6-OHDA lesion at P1 followed by an unilateral intranigral VM graft at P3. Fluorescence photomicrographs were taken from the SNpr at high power. Many of the TH-positive neurons within the grafts were retrogradely labeled with FG (indicated by long arrows in A, B), and only few cells were either only TH positive (indicated by arrowheads in A, G) or FG labeled (indicated by shorter arrows in $H$ ). Scale bar, $50 \mu \mathrm{m}$. 

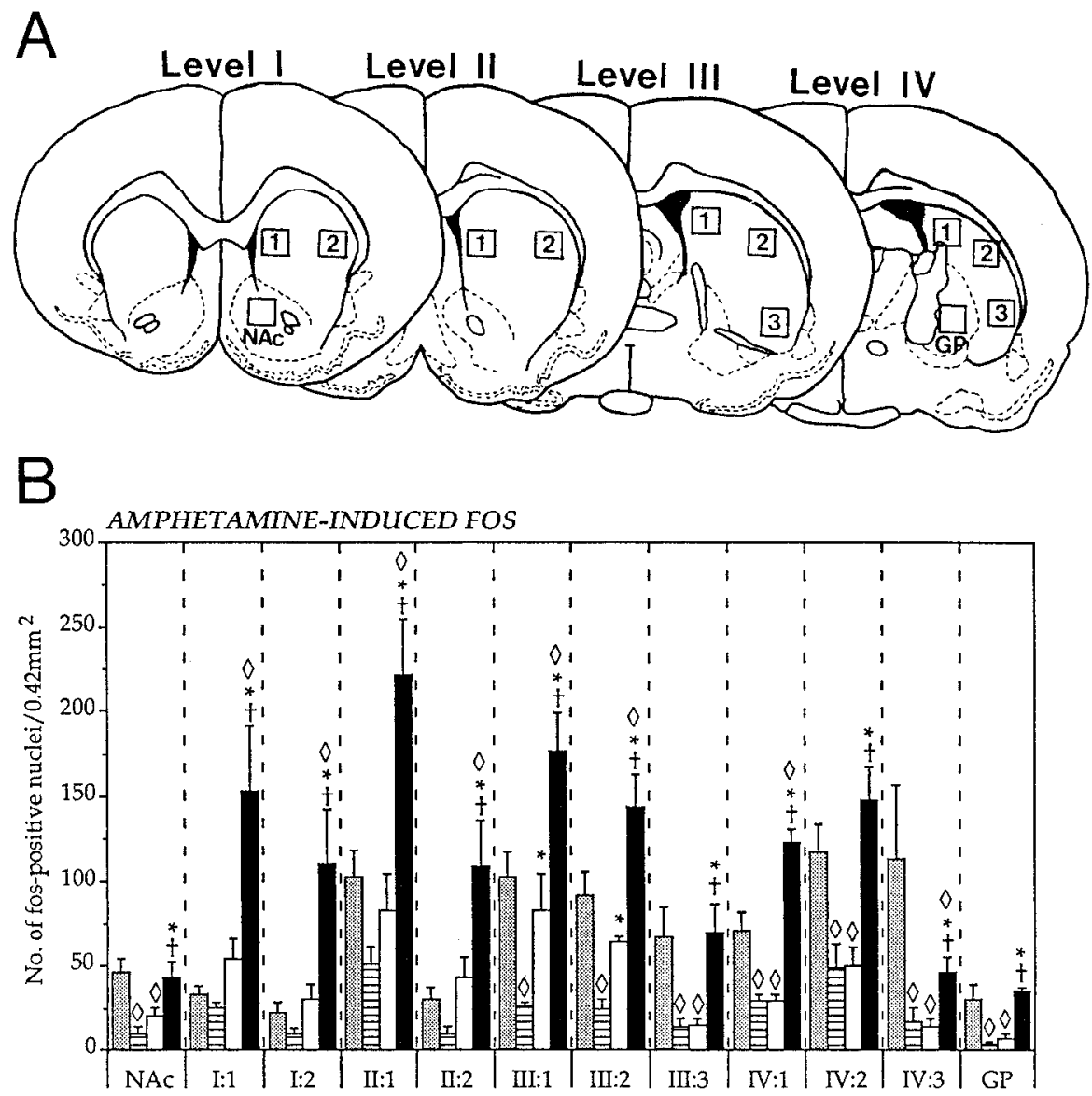

Figure 6. Amphetamine- $(B)$ and apomorphine- $(C)$ induced Fos expression. Densities of Fos-positive nuclei in normal $(n=4)$, lesion-only $(n=5)$, and VM-grafted $(n=5)$ animals were measured in ten areas at four different rostrocaudal levels of the caudate-putamen, as well as in the nuclcus accumbens and GP, as illustrated in $A$. The right and left side of the normal and the lesion-only animals have been averaged, since the two sides did not differ significantly from each other. Data was analyzed with ANOVA and NewmanKeuls post hoc test.

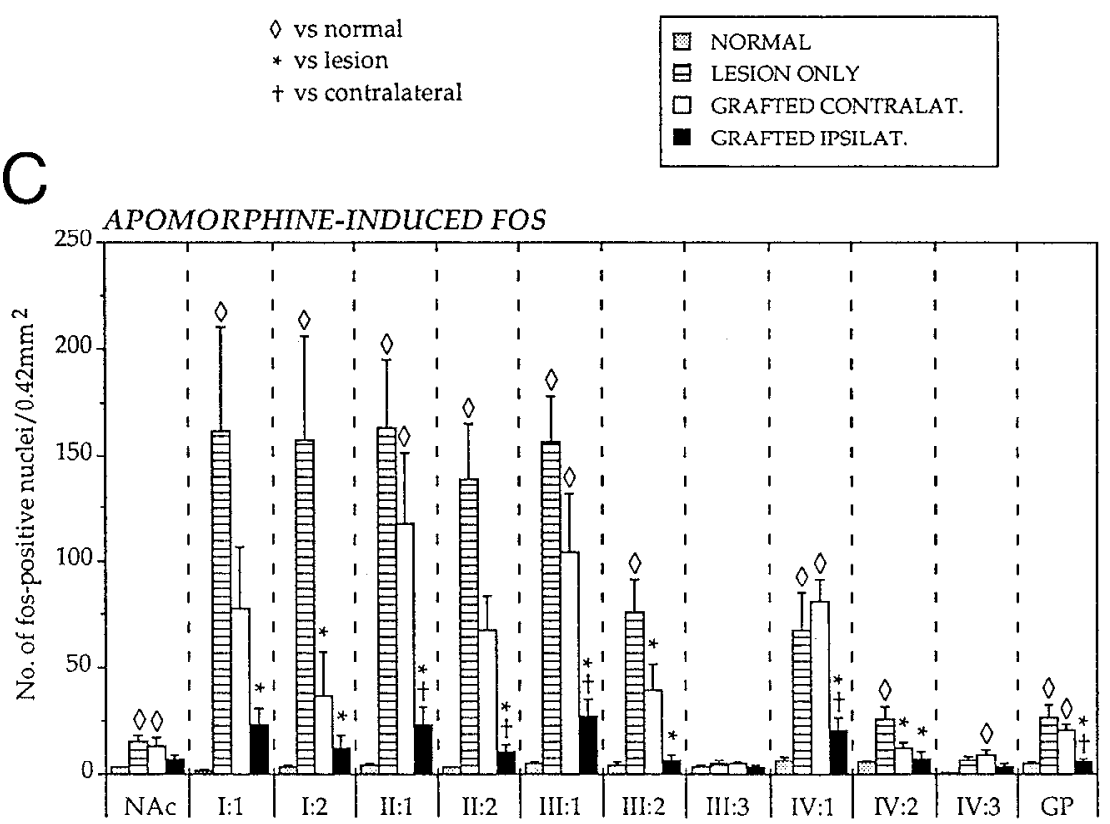

Factors that might stimulate and guide long-distance axon growth from intranigral VM grafts in neonatal hosts

Previous studies on homotopic intranigral VM grafts in adult rats have revealed outgrowth of processes with a dendritic morphology into the SNpr, but no significant axon outgrowth from the transplants even into the immediate vicinity of the grafts (Björklund et al., 1983b; Robertson et al., 1991; Nikkhah et al., 1994b). In a previous study (Nikkhah et al., 1994b) we have used the micro- transplantation technique to implant multiple small deposits of VM cell suspension with minimal trauma into the adult SN. Even in these animals, where the TH-positive neurons had integrated well into the host $\mathrm{SN}$, we still could not observe any signs of directed TH-positive axonal outgrowth along the nigrostriatal pathway. The developmental age of the host is thus likely to be an important determining factor for the reformation of the nigrostriatal pathway by transplanted rat fetal dopaminergic nigral neurons. 


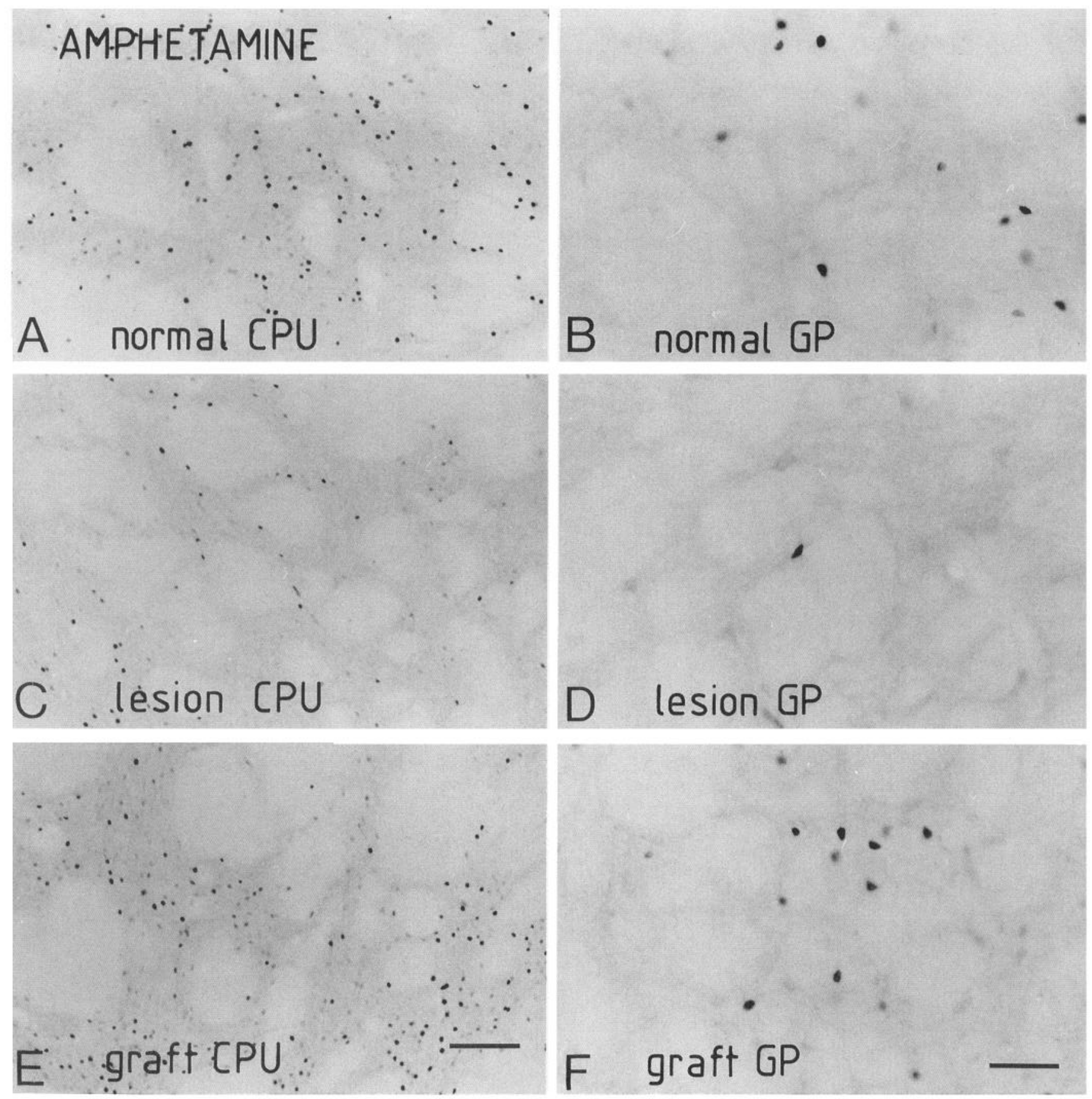

Figure 7. Photomicrographs illustrating Fos-positive nuclei after amphetamine treatment $(5 \mathrm{mg} / \mathrm{kg}$, i.p.) of a normal $(A, B)$, lesioned $(C, D)$, and VM-grafted $(E, F)$ animal in the caudate-putamen (Level IV, left row) and GP (right row). Scale bars: $A, C$, and $E, 100 \mu \mathrm{m} ; B, D$, and $F, 50 \mu \mathrm{m}$.

The failure of VM grafts to express long-distance axonal growth in adult hosts, as opposed to what has been found here after implantation into neonatal rats, would speak in favor of a more permissive graft environment during the early postnatal period. In fact, previous studies have demonstrated long axon growth from fetal neural grafts in neonatal hosts in different experimental models. For example, retinae transplanted onto the surface or into the parenchyma of the midbrain exhibit a target directed outgrowth towards the superior colliculus in a highly specific manner (Hankin and Lund, 1987, 1990). Fetal cortical (Floeter and Jones, 1984; Castro et al., 1985; Stanfield and
O'Leary, 1985; Heffner et al., 1990) and hippocampal neurons (Sunde et al., 1984; Zimmer et al., 1987) transplanted into neonatal animals can establish organotypic afferent and efferent connections with the host brain restoring part of the normal neuronal circuitry.

As regards the development of the intrinsic dopaminergic system, the nigrostriatal pathway projections are already established in the early postnatal period (P1-3), whereas the expansion of the terminal innervation network in the striatum is still in progress (Specht et al., 1981a,b; Voorn et al., 1988). The grafted VM cells, on the other hand, were taken from the fetuses at a time 

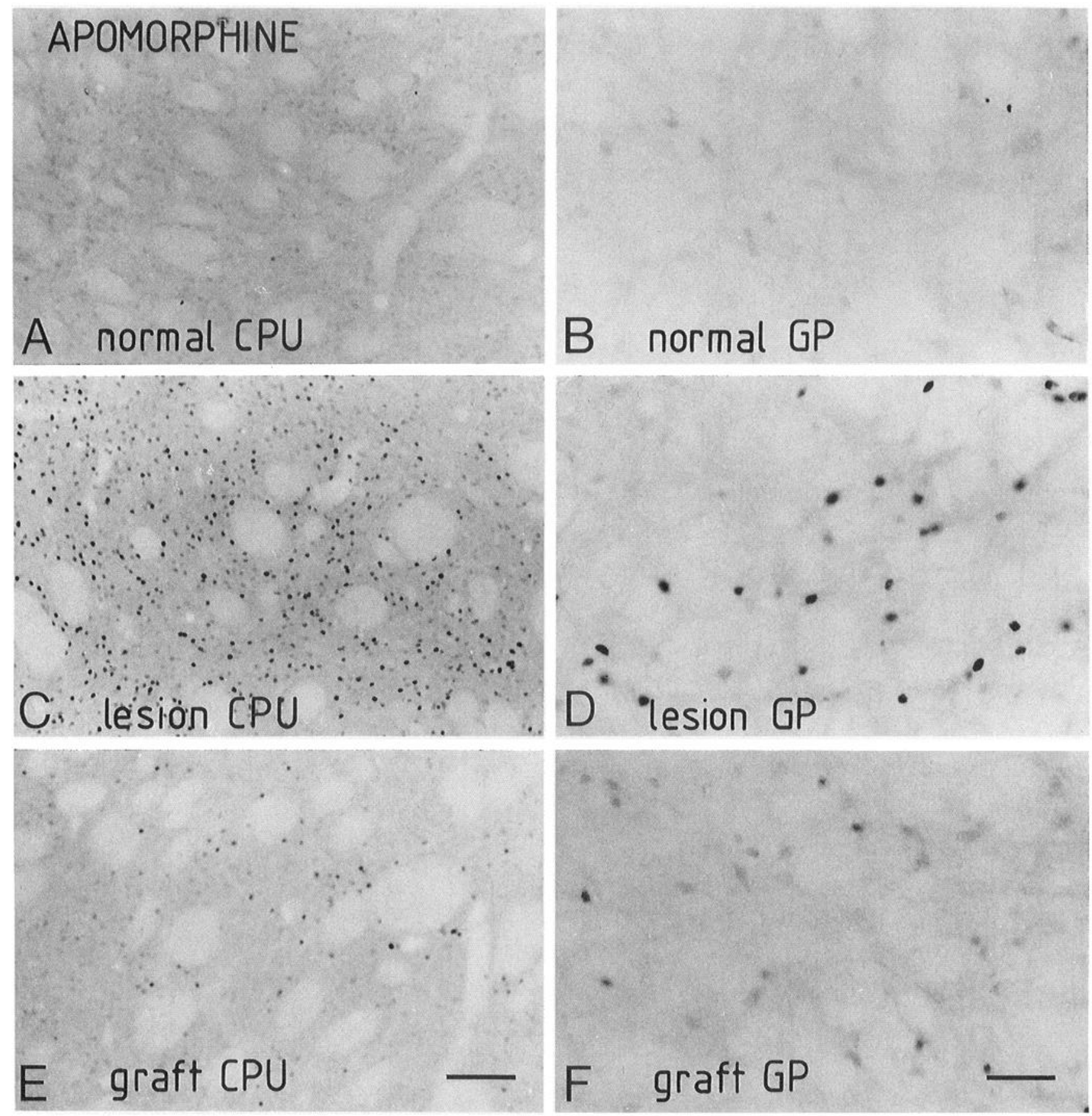

Figure 8. Photomicrographs illustrating Fos-positive nuclei after apomorphine treatment $(0.25 \mathrm{mg} / \mathrm{kg}, \mathrm{s.c}$.) of a normal $(A, B)$, lesion-only $(C, D)$, and VM-grafted $(E, F)$ animal in the caudate-putamen (level II, left row) and GP (right row). Scale bars: $A, C$, and $E, 100 \mu \mathrm{m} ; B, D$, and $F, 50$ $\mu \mathrm{m}$.

point (E14) when the dopaminergic nigral neurons are starting to elicit axons rostrally (Specht et al., 1981a; Voorn et al., 1988). The 6-OHDA lesion (at P1) and the transplantation of E14 nigral cells (at P3) have thus been performed in the present study during a period of development when the nigrostriatal pathway is in an active growth phase. Interestingly, the development of the host environment was $10 \mathrm{~d}$ ahead of that of the implanted nigral cells. Despite this developmental mismatch the fetal nigral neurons retained their capacity to extend axons along the nigrostriatal pathway and elaborated a substantial terminal network in the caudate-putamen, that is, the appropriate target of the intrinsic nigral neurons (Nikkhah et al., 1994b). This raises interesting questions as regards the cellular and molecular mechanisms underlying axonal guidance and pathway formation. It should be noted, on the other hand, that the implanted TH-positive neurons remained at or near the site of implantation, which suggest that the migratory mechanisms which normally allow the fetal dopaminergic neurons to move into the pars compacta layer of the SN during early development are not available to them in the environment of the early postnatal brain. 
The ability of fetal nigral neurons implanted in the early postnatal period to exert long-distance growth in white matter tracts implies that at this point in development growth-promoting factors dominate over possible growth-inhibiting factors. This has been suggested also in studies of ectopic intrastriatal VM grafts in neonatal pups, where a more extensive migration of grafted dopaminergic cells and TH-positive fiber outgrowth has been observed (Snyder-Keller et al., 1989; Herman et al., 1991). The candidate factors, capable of influencing axonal growth in the developing CNS, might be both soluble and membrane bound and have been extensively discussed elsewhere (Crossin et al., 1990; Steindler et al., 1990, 1993). Of particular interest for the findings of the present study is the work of by McKeon et al. (1991). They observed minimal expression of certain extracellular matrix (ECM) molecules (chondroitin-6-sulfate proteoglycan and cytotactin/tenascin) within and around experimentally induced glial scars in the neonatal cortex, while the same lesion procedure produced an intense upregulation of both ECM molecules together with a strong GFAP expression in adult animals. Potential growth promoting substrate factors, such as laminin, collagen and fibronectin, were expressed equally in both age groups. Glial tissue, explanted from the lesioned site of neonatal animals, supported neurite outgrowth, whereas cortical scar tissue from adult animals greatly reduced neurite extension from chick retinal ganglion cells in vitro. McKeon et al. (1991) concluded from these observations that the regenerative potential seen in neonates is more closely linked to the absence or low expression of growth-inhibiting molecules rather than increased transient expression of growth-promoting substrate molecules or glial factors. These two mechanisms, in fact, are likely to complement each other.

\section{Characteristics of the $T H$-positive reinnervation of the striatum}

Consistent with previous reports (Snyder et al., 1986; Herman et al., 1991) the intraventricular injection of 6-OHDA at PI resulted in a destruction of nearly all $\mathrm{TH}$-positive neurons in the $\mathrm{SN}$ and an almost complete denervation of the striatum, whereas the TH-positive neurons in the VTA and the TH-positive innervation of the nucleus accumbens and the olfactory tubercle were partially spared. The reinnervation pattern formed from the intranigral VM transplants was densest medially and demonstrated a consistent medial-to-lateral gradient within the ipsilateral caudate-putamen. A similar preference of $\mathrm{TH}$-positive fiber outgrowth towards the medial half of the striatum has been reported from intrastriatal VM grafts in neonatal pups (Snyder-Keller et al., 1989), although the underlying cause remains unknown. It may be speculated that specific patterns in the distribution of ECM molecules within the striatum might guide or direct $\mathrm{TH}-$ positive fiber outgrowth more medially during this period of development. In fact, Voorn et al. (1988) have suggested that the development of the dopaminergic innervation of the rostral striatum follows a "spatiotemporal gradient" from ventrolateral to dorsomedial during the late embryonic-early postnatal period.

\section{Characteristics of the TH-negative reinnervation of the striatum}

Fiber outgrowth from intrastriatal VM transplants has been well characterized (see, e.g., Björklund et al., 1983b; Schultzherg et al., 1984; Abrous et al., 1988; Mahalik and Clayton, 1991; Mendez et al., 1991). In the present study we found, in addition to the $\mathrm{TH}$-positive neurons, also moderate numbers of TH-negative neurons retrogradely labeled from the intrastriatal $F G$ injection site within the intranigral VM transplants. In a conbined innmunohistochemical and retrograde tracing study on fetal intrastriatal VM grafts in adult rats, Mahalik and Clayton (1991) have demonstrated that the second most prominent neuron type projecting from VM grafts to the host striatum (beside the dopamine neurons) are serotonergic cells, most likely derived from portions of the mesencephalic raphe included in the VM dissection (Doucet et al., 1989). It is interesting to note in this context that the neonatal dopamine denervation stimulates a sprouting of serotoninergic afferents from raphe neurons into the striatum (Snyder et al., 1986). This sprouting response, in turn, is not influenced by a "competitive" reinnervation of $\mathrm{TH}$-positive fibers derived from ectopic intrastriatal VM grafts in the neonates (Snyder-Keller et al., 1989; Abrous et al., 1993).

\section{Functional reinnervation of the striatum by intranigral VM grafts as revealed by the induction of Fos}

The expression of the immediate-early gene c-fos through dopamine receptor-mediated mechanisms has been well characterized, both on the protein (Graybiel et al., 1990; LaHoste et al., 1993) and mRNA (Johansson et al., 1994) level. In the present study amphetamine-induced Fos expression in normal rats was seen at high levels throughout the striatal complex, whereas only very few Fos-positive nuclei were encountered in the striatum after apomorphine treatment, which is consistent with a previous report (Cenci et al., 1992). Lesion-only animals exhibited the reverse picture, that is, a reduced expression in response to amphetamine, and a greatly increased response after apomorphine (given at $0.05 \mathrm{mg} / \mathrm{kg}$, a dose which activates only supersensitive dopamine receptors). The changes seen after the neonatal 6-OHDA lesion was qualitatively similar but somewhat lower in magnitude than those observed after a complete 6-OHDA nigrostriatal bundlc lesion in adult rats (Cenci ct al., 1992). Animals with intranigral VM grafts implanted at P3 demonstrated a significant hyperexpression of Fos in most areas of the striatum as compared to normal intact controls, and normalized Fos expression in the nucleus accumbens and the globus pallidus on the side ipsilateral to the grafts. Apomorphine-induced hyperexpression, as seen in the neonatally 6-OHDA-lesioned animals, was completely reversed by the intranigral VM grafts in all areas examined ipsilateral to the transplants. Interestingly, there was a significant effect also in some areas on the contralateral side. Similar results have been reported with ectopic intrastriatal VM grafts in adult (Abrous et al., 1992; Cenci et al., 1992), and neonatal (Snyder-Keller, 1991; Abrous et al., 1993) hosts. It was concluded from those studies that the normalization of striatal Fos expression was mediated via dopamine released from graftderived TH-positive fibers, which had reinnervated the striatum, although the graft-induced effect clearly extended into nonreinnervated, more distant areas of the striatum as well (Cenci et al., 1992). The normalization of apomorphine-induced Fos expression obtained by intranigral VM grafts in the neonates strongly suggests that dopamine released from the intrastriatal terminals of grafted dopaminergic neurons located in the SN region had reversed the 6-OHDA lesion-induced supersensitivity of striatal D1 and/or D2 receptors. Similarly, the restoration of amphetamine-induced Fos expression indicates that dopamine released from the graft-derived axon terminals in the striatum is capable of inducing a functional dopamine-receptor mediated response in the striatal projection neurons of the host. In adult recipients, dopamine released from intrastriatal VM grafts has been shown to recover to between 40 and $85 \%$ of control values 
(Zetterström et al., 1986; Strecker et al., 1987; Rioux et al., 1991), and supranormal dopamine receptor levels are reversed back to normal (Dawson et al., 1991; Chritin et al., 1992). Similar graft-mediated mechanisms might contribute to the effects seen in the graft-reinnervated striatum in the present study. The effect seen on apomorphine-induced Fos expression on the side contralateral to the graft, which occurred in the absence of any clear-cut ' $\mathrm{I}$ 'H-positive fiber projection to that side, is most probably explained by some kind of functional interaction between the two sides, as noted also in other studies (Nieoullon et al., 1977; Leviel et al., 1979, 1981).

In conclusion, intranigral VM grafts transplanted homotopically into the $\mathrm{SN}$ region in the neonatal brain revealed a novel pattern of morphological integration, which permits the fetal dopamine neurons to reestablish a functional nigrostriatal pathway. The behavioral analysis of the present animals, reported in the following companion article (Nikkhah et al., 1995), provides evidence that the reformation of the nigrostriatal pathway is associated with recovery of certain lesion-induced deficits, such as spontaneous and stress-induced turning and skilled forelimb use, which are resistant to transplant-induced behavioral recovery after ectopic intrastriatal VM grafts in neonatal pups (Herman et al., 1991; Abrous et al., 1993a,b). The microtransplantation strategy, therefore, may provide new insights into the mechanisms controlling long-distance axon growth in the nigrostriatal system and contribute to the ongoing efforts to achieve more complete functional recovery with fetal VM transplants in experimental and clinical neurotransplantation in Parkinson's disease.

\section{References}

Abrous N, Guy J, Vigny A, Calas A, Le MM, Herman JP (1988) Development of intracerebral dopaminergic grafts: a combined immunohistochemical and autoradiographic study of its time course and environmental influences. J Comp Neurol 273:26-41.

Abrous DN, Torres EM, Annett LE, Reading PJ, Dunnett SB (1992) Intrastriatal dopamine-rich grafts induce a hyperexpression of Fos protein when challenged with amphetamine. Exp Brain Res 91:181190.

Abrous DN, Choulli K, Rouge-Pont F, Simon H, Le Moal M, Herman JP (1993a) Effects of intracerebral dopaminergic grafts on behavioural deficits induced by neonatal 6-hydroxydopamine lesions of the mesotelencephalic dopaminergic pathway. Neuroscience 54:499-511.

Abrous DN, Manier M. Mennicken F, Feuerstein C, Le MM, Herman JP (1993b) Intrastriatal transplants of embryonic dopaminergic neurons counteract the increase of striatal enkephalin immunostaining but not serotoninergic sprouting elicited by a neonatal lesion of the nigrostriatal dopaminergic pathway. Eur J Neurosci 5:128-136.

Abrous DN, Herman JP, LeMoal M (1993c) Dopaminergic grafts in neonatally lesioned neostriatum induce c-fos hyperexpression. Soc Neurosci Abstr 19:284.10.

Björklund A (1992) Dopaminergic transplants in experimental parkinsonism: cellular mechanisms of graft-induced functional recovery. Curr Opin Neurobiol 2:683-689.

Björklund A, Stenevi U, Schmidt RH, Dunnett SB, Gage FH (1983a) Intracerebral grafting of neuronal cell suspensions. I. Introduction and general methods of preparation. Acta Physiol Scand 522:1-7.

Björklund A, Stenevi U, Schmidt RH, Dunnett SB, Gage FH (1983b) Intracerebral grafting of neuronal cell suspensions. II. Survival and growth of nigral cell suspensions implanted in different brain sites. Acta Physiol Scand 522:9-18.

Björklund A, Dunnett SB, Nikkhah G (1994) Nigral transplants in the rat Parkinson model. In: Functional neural transplantation (Dunnett SR, Björklund A, eds), pp 47-69. New York: Raven.

Castro AJ, Zimmer J, Sunde N, Bold EL (1985) Transplantation of fetal cortex to the brain of newborn rats: a retrograde fluorescent analysis of callosal and thalamic projections from transplant to host. Neurosci Lett 60:283-288.

Cenci MA, Kalen P, Mandel RJ, Wictorin K, Björklund A (1992) Do- paminergic transplants normalize amphetamine- and apomorphine induced Fos expression in the 6-hydroxydopamine-lesioned striatum. Neuroscience 46:943-957.

Chritin M, Savasta M, Mennicken F, Bal A, Abrous DN, Le MM, Feuerstein C, Herman JP (1992) Intrastriatal dopamine-rich implants reverse the increase of dopamine D-2 receptor mRNA levels caused by lesion of the nigrostriatal pathway: a quantitative in situ hybridization study. Eur J Neurosci 4:663-672.

Crossin KL, Prieto AL, Hoffman S, Jones FS, Friedlander DR (1990) Expression of adhesion molecules and the establishment of boundaries during embryonic and neural development. Exp Neurol 109:618.

Cunningham MG, McKay RDG (1993) A hypothermic miniaturized stereotaxic instrument for surgery in newborn rats. J Neurosci Methods $47: 105-114$.

Cunningham MG, Nikkhah G, McKay RDG (1993) Grafting immortalized hippocampal cells into the brain of the adult and the newborn rat. Neuroprotocols $3: 260-272$.

Davies SJA, Field PM, Raisman G (1993) Long fibre growth by axons of embryonic mouse hippocampal neurons microtransplanted into the adult rat fimbria. Eur J Neurosci 5:95-106.

Davies SJA, Field PM, Raisman G (1994) Long interfascicular axon growth from embryonic neurons transplanted into adult myelinated tracts. J Neurosci 14:1596-1612.

Dawson TM, Dawson VL, Gage FH, Fisher LJ, Hunt MA and Wamsley JK (1991) Functional recovery of supersensitive dopamine receptors after intrastriatal grafts of fetal substantia nigra. Exp Neurol 111:282292.

Doucet G, Murata Y, Brundin P, Bosler O, Mons N, Geffard M, Ouimet CC, Björklund A (1989) Host afferents into intrastriatal transplants of fetal ventral mesencephalon. Exp Neurol 106:1-19.

Dunnett SB, Björklund A, Schmidt RH, et al. (1983) Intracerebral grafting of neuronal cell suspensions. IV. Behavioural recovery in rats with unilateral 6-OHDA lesions following implantation of nigral cell suspensions in different forebrain sites. Acta Physiol Scand 522: $29-37$.

Dunnett SB, Rogers DC, Richards SJ (1989) Nigrostriatal reconstruction after 6-OHDA lesions in rats: combination of dopamine-rich nigral grafts and nigrostriatal 'bridge' grafts. Exp Brain Res 75:523535.

Floeter MK, Jones EJ (1984) Connections made by transplants to the cerebral cortex of rat brains damaged in utero. J Neurosci 4:141150 .

Graybiel AM, Moratalla R, Robertson HA (1990) Amphetamine and cocaine induce drug-specific activation of the c-fos gene in striosomematrix compartments and limbic subdivisions of the striatum. Proc Natl Acad Sci USA 87:6912-6916.

Hankin MH, Lund RD (1987) Role of the target in directing the outgrowth of retinal axons: transplants reveal surface-related and surface-independent cues. J Comp Neurol 263:455-466.

IIankin MII, Lund RD (1990) Induction of target-directed optic axon outgrowth: effect of retinae transplanted to anophthalmic mice. Dev Biol 138:136-146.

Heffner CD, Lumsden A, O'Leary D (1990) Target control of collateral extension and directional axon growth in the mammalian brain. Science 247:217-220.

Herman JP, Choulli K, Geffard M, Nadaud D, Taghzouti K, LeMoal M (1986) Reinnervation of the nucleus accumbens and frontal cortex of the rat by dopaminergic grafts and effects on hoarding behavior. Brain Res 372:210-216.

Herman JP, Abrous DN, Le MM (1991) Anatomical and behavioral comparison of unilateral dopamine-rich grafts implanted into the striatum of neonatal and adult rats. Neuroscience 40:465-475.

Iwashita Y, Kawaguchi S, Murata M (1994) Restoration of function by replacement of spinal cord segments in the rat. Nature 367:167-170.

Johansson B, Lindström K, Fredholm BB (1994) Differences in the regional and cellular localization of c-fos messenger RNA induced by amphetamine, cocaine and caffeine in the rat. Neuroscience 59 : $837-849$.

LaHoste GJ, Yu J, Marshall JF (1993) Striatal Fos expression is indicative of dopamine D1/D2 synergism and receptor supersensitivity. Proc Natl Acad Sci USA 90:7451-7455.

Leviel V, Cheramy A, Glowinski J (1979) Role of the dendritic release of dopamine in the reciprocal control of the two nigro-striatal dopaminergic pathways. Nature 280:236-239. 
Leviel V, Chesselet MF, Glowinski J, Cheramy A (1981) Involvement of the thalamus in the asymmetric effects of unilateral sensory stimuli on the two nigrostriatal dopaminergic pathways in the cat. Brain Res 223:257-272.

Li Y, Raisman G (1993) Long axon growth from embryonic neurons transplanted into myelinated tracts of the adult rat spinal cord. Brain Res 629:115-127.

Lund RD, Hankin MH, Sefton AJ, Perry VH (1988) Conditions for optic axon outgrowth. Brain Behav Evol 31:218-226.

Mahalik TJ, Clayton GH (1991) Specific outgrowth from neurons of ventral mesencephalic grafts to the catecholamine-depleted striatum of adult hosts. Fxp Neurol 113:18-27.

McKeon RJ, Schreiber RC, Rudge JS, Silver J (1991) Reduction of neurite outgrowth in a model of glial scarring following CNS injury is correlated with the expression of inhibitory molecules on reactive astrocytes. J Neurosci 11:3398-3411.

Mendez I, Elisevich K, Flumerfelt BA (1991) Dopaminergic innervation of substance P-containing striatal neurons by fetal nigral grafts: an ultrastructural double-labeling immunocytochemical study. J Comp Neurol 308:66-78.

Nieoullon A, Cheramy A, Glowinski J (1977) Interdependence of the nigrostriatal dopaminergic system on the two sides of the brain in the cat. Science 198:416-418.

Nikkhah G, Duan W-M, Knappe U, Jödicke A, Björklund A (1993) Restoration of complex sensorimotor behavior and skilled forelimb use by a modified nigral cell suspension transplantation approach in the rat Parkinson model. Neuroscience 56:33-43.

Nikkhah G, Cunningham MG, Jödicke A, Knappe U, Björklund A (1994a) Improved graft survival and striatal reinnervation by microtransplantation of fetal nigral cell suspensions in the rat Parkinson model. Brain Res 633:133-143.

Nikkhah $G$, Bentlage C, Cunningham MG, Björklund A (1994b) Intranigral fetal dopamine grafts induce behavioral compensation in the rat Parkinson model. J Neurosci 14:3449-3461.

Nikkhah G, Olsson M, Eberhard J, Bentlage C, Cunningham MG, Björklund A (1994c) A microtransplantation approach for cell suspension grafting in the rat Parkinson model. A detailed account of the methodology. Neuroscience 63:57-72.

Nikkhah G, Cunningham MG, McKay R, Björklund A (1995) Dopaminergic microtransplants into the substantia nigra of nconatal rats with bilateral 6-OHDA lesions. II. Transplant-induced behavioral recovery. J Neurosci 15:3562-3570.

Omlin FX, Waldmeyer $\mathcal{J}$ (1986) Minisegments of newborn rat optic nerves in vitro: gliogenesis and myelination. Exp Brain Res 65:189199.

Paxinos G, Watson C (1986) The rat brain in stereotaxic coordinates. New York: Academic.

Rioux L, Gaudin DP, Bui LK, Gregoire L, DiPaolo T, Bedard PJ (1991) Correlation of functional recovery after a 6-hydroxydopamine lesion with survival of grafted fetal neurons and release of dopamine in the striatum of the rat. Neuroscience 10:123-131.

Robertson GS, Fine A, Robertson HA (1991) Dopaminergic grafts in the striatum reduce $\mathrm{D}-1$ but not $\mathrm{D}-2$ receptor-mediated rotation in 6-OHDA-lesioned rats. Brain Res 539:304-311.

Robertson HA (1992) Dopamine receptor interactions: some implications for the treatment of Parkinson's disease. Trends Neurosci 15 201-206.

Schnell L, Schwab ME (1990) Axonal regeneration in the rat spinal cord produced by an antibody against myelin-associated neurite growth inhibitors. Nature 343:269-272.

Schultzberg M, Dunnett SB, Björklund A, et al. (1984) Dopamine and cholecystokinin immunoreactive neurones in mesencephalic grafts reinnervating the neostriatum: evidence for selective growth regula tion. Neuroscience 12:17-32.

Schwab ME (1990) Myelin-associated inhibitors of neurite growth and regeneration in the CNS. Trends Neurosci 13:452-456.

Schwab ME, Kapfhammer JP, Bandtlow CE (1993) Inhibitors of neurite growth. Annu Rev Neurosci 16:565-595.

Snyder AM, Zigmond MJ, Lund RD (1986) Sprouting of serotononinergic afferents into striatum after dopamine-depleting lesions in infants rats: a retrograde transport and immunocytochemical study. J Comp Neurol 245:274-281.

Snyder-Keller A (1991) Striatal c-fos induction by drugs and stress in neonatally dopamine-depleted rats given nigral transplants: importance of NMDA activation and relevance to sensitization phenomena. Exp Neurol 113:155-165.

Snyder-Keller AM, Carder RK, Lund RD (1989) Development of do pamine innervation and turning behavior in dopamine-depleted infant rats receiving unilateral nigral transplants. Neuroscience 30:779-794.

Spechi LA, Pickel VM, Joh T, Reis DJ (1981a) Light-microscopic intmunocytochemical localization of tyrosine hydroxylase in prenatal rat brain. I. Early ontogeny. J Comp Neurol 199:233-253.

Specht LA, Pickel VM, Joh TH, Keis DJ (1981b) Light-microscopic immunocytochemical localization of tyrosine hydroxylase in prenatal rat brain. II. Late ontogeny. J Comp Neurol 199:255-276.

Stanfield BB, O'Leary D (1985) Fetal occipital cortical neurones transplanted to the rostral cortex can extend and maintain a pyramidal tract axon. Nature 313:135-137.

Steindler DA (1993) Glial boundaries in the developing nervous system. Annu Rev Neurosci 16:445-470.

Steindler DA, O'Brien TF, Laywell E, Harrington K, Faissner A, Schachner M (1990) Boundaries during normal and abnormal brain development: in vivo and in vitro studies of glia and glycoconjugates. Exp Ncurol 109:35-56.

Strecker R, Sharp T, Brundin P, Zetterström T, Ungerstedt U, Bjorklund A (1987) Autoregulation of dopamine release and metabolism by intrastriatal nigral grafts as revealed by intracerebral dialysis. Neuroscience 22:169-178.

Sunde N, Laurberg S, Zimmer J (1984) Brain grafts can restore irradiation-damaged neuronal connections in newborn rats. Nature 310 : $51-53$.

Voorn P, Kalsbeek A, Jorritsma BB, Groenewegen HJ (1988) The preand postnatal development of the dopaminergic cell groups in the ventral mesencephalon and the dopaminergic innervation of the striatum of the rat. Neuroscience 25:857-887.

Wictorin K, Ouimet CC, Björklund A (1989) Intrinsic organization and connectivity of intrastriatal striatal transplants in rats as revealed by DARPP-32 immunohistochemistry: specificity of connections with the lesioned host brain. Eur J Neurosci 1:690-701.

Wictorin K, Brundin P, Gustavii B, Lindvall O, Björklund A (1990) Reformation of long axon pathways in adult rat central nervous system by human forebrain neuroblasts. Nature 347:556-558.

Wictorin K, Brundin P, Sauer H, Lindvall O, Björklund A (1992) Long distance directed axonal growth from human dopaminergic mesencephalic neuroblasts implanted along the nigrostriatal pathway in 6-hydroxydopamine lesioned adult rats. J Comp Neurol 323:475-494.

Zetterström T, Herrera MM, Ungerstedt U (1986) Simultaneous measurement of dopamine release and rotational behaviour in 6-hydroxydopamine denervated rats using intracerebral dialysis. Brain Res 376: $1-7$.

Zimmer J, Finsen B, Sorensen T, Sunde N (1987) Hippocampal transplants: synaptic organization, their use in repair of neural circuits and mouse to rat xenografting. In: Glial-neuronal communication in development and regeneration (Althaus $\mathrm{H}$, Seifert W, eds), pp 545-563. Heidelberg: Springer. 